\title{
USO EN PUBLICIDAD DE FOTOGRAFÍAS DE BANCOS DE IMÁGENES ESPAÑOLES
}

\author{
Juan-Carlos Marcos-Recio, Juan-Miguel Sánchez-Vigil y María Olivera-Zaldua
}



Juan-Carlos Marcos-Recio, profesor titular del Depto. de Biblioteconomía y Documentación de la Universidad Complutense de Madrid, es especialista en documentación en medios de comunicación y experto en educación a distancia. Investiga la documentación y la publicidad, donde ha publicado varios libros y artículos que analizan las aportaciones que los documentalistas/planners pueden desarrollar en esta materia, un campo donde la investigación es fundamental para el trabajo creativo, la planificación, el conocimiento del producto, el mercado y la competencia. Creador y director del Portal Publidocnet (Centro Documental para la Conservación del Patrimonio Publicitario Español), con el objetivo de reunir y conservar los estudios, las investigaciones y las campañas publicitarias. Co-director del blog Documentación en Mi+d.

Secc. Dep. de Biblioteconomía y Documentación Facultad de Ciencias de la Información, UCM Av. Complutense, s/n. 28040 Madrid jmarcos@ccinf.ucm.es http://www.publidocnet.com

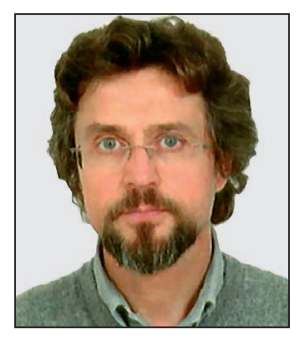

Juan-Miguel Sánchez-Vigil. Dr. en ciencias de la información por la Facultad de CC. de la Información de la Univ. Complutense de Madrid. Profesor titular en la Fac. de Documentación de la misma universidad. Editor y fotógrafo, colaborador de la editorial Espasa-Calpe y de varias revistas especializadas, entre ellas la literaria Ínsula. Ha publicado obras sobre documentación fotográfica e iconográfica, de las que destaca Revistas ilustradas en España (2008), Del daguerrotipo a la Instamatic (2007), El documento fotográfico (2006) y Diccionario de fotografía (2002). Ha sido comisario de las exposiciones fotográficas de Alfonso y Calvache, jurado y miembro de comités científicos. En materia de edición ha publicado Calpe, paradigma editorial (2005) y ha coordinado el monográfico de la revista Ínsula dedicado a la Colección Austral (2009). Co-director del blog Documentación en Mi+d.

Depto. de Biblioteconomía y Documentación, UCM Santísima Trinidad, 37. 28010 Madrid jmvigil@ccinf.ucm.es

http://www.madrimasd.org/blogs/documentacion

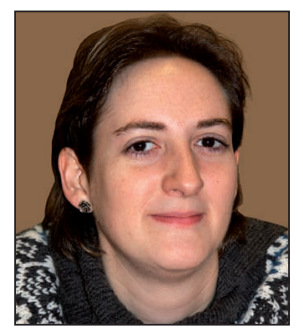

María Olivera-Zaldua, doctora en documentación por la Universidad Complutense de Madrid y profesora de la Facultad de Ciencias de la Documentación, de la misma universidad, es documentalista de la editorial Espasa-Calpe, habiendo participado en varias obras. Forma parte del equipo de investigación del Archivo del Ateneo de Madrid. Ha colaborado en los libros Revistas ilustradas en España y Del daguerrotipo a la Instamatic, y es autora de varios artículos y comunicaciones en congresos nacionales e internacionales. Recientemente presentó el libro Chamberí en Blanco y Negro 1875-1975, del que es coautora con Juan-Miguel Sánchez-Vigil. Colabora en el blog Documentación en Mi+d.

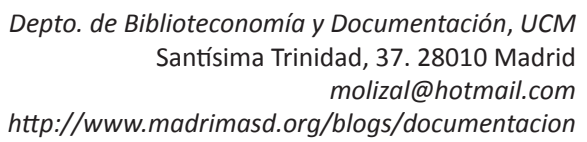

\section{Resumen}

Agencias y fototecas ofrecen millones de documentos fotográficos dispuestos para su uso. En la última década el sector ha cambiado radicalmente por el impacto digital y por la globalización del negocio, renovando las estructuras, realizando grandes inversiones en la digitalización y, al mismo tiempo, generando nuevos modelos de comercialización. Se estudia el uso en publicidad de las fotografías de los bancos de imágenes comerciales en España, tomando como referencia siete agencias de diferentes tamaños y con distintos objetivos.

\section{Palabras clave}

Agencias, Bancos de imágenes, Fotografía, Fotografía publicitaria, Fototecas, Publicidad, Aisa, Asa, Album, Latinstock, Oronoz, Prisma, Quickimage. 
Title: Use of photographs from Spanish stock photography banks in advertising

\section{Abstract}

Agencies and image banks offer millions of photographs for use in advertising and publishing. During the last decade the sector has undergone a radical change due to the digital impact and the globalization of the business. Structures have been refurbished, major investments in digitization have been made and at the same time, new marketing models have been adopted. This study reviews the use of photographs from the commercial stock photography banks in advertising in Spain. Seven agencies of different size and objectives have been chosen as a reference.

\section{Keywords}

Agencies, Stock photography banks, Photography, Advertising photography, Photo libraries, Advertising, Aisa, Asa, Album, Latinstock, Oronoz, Prisma, Quickimage.

Marcos-Recio, Juan-Carlos; Sánchez-Vigil, Juan-Miguel; Olivera-Zaldua, María. "Uso en publicidad de fotografías de bancos de imágenes españoles". El profesional de la información, 2011, v. 20, n. 4, pp. 384-391.

http://dx.doi.org/10.3145/epi.2011.jul.04

\section{Introducción}

En la fotografía primero es el hecho de mirar y después las valoraciones documentales, informativas y artísticas. Hasta comienzos de la década de los 30 del siglo XX el elemento ilustrativo en publicidad fue el dibujo, esquema que rompieron las vanguardias al emplear la foto como vehículo de expresión en el periodo de entreguerras. Posteriormente, la comercialización de productos ha hecho de la fotografía publicitaria una de las más importantes actividades, incluyendo tanto la producción como el movimiento de las imágenes. Casi todas las estrategias de las agencias publicitarias basan su campaña en la fotografía y la utilizan para lanzar mensajes y fijar ideas. Con ella se quiere impactar, pero también recordar la marca que se anuncia, de ahí la importancia de seleccionar una buena imagen evitando la polisemia, porque no siempre queda claro lo que se quiere transmitir.

La imagen en publicidad se ha convertido en un referente imprescindible porque ayuda a conocer los parámetros sociales y culturales de los consumidores. El consumo de fotografías en prensa ha aumentado con internet, y también ha aumentado en la publicidad exterior, donde los nuevos

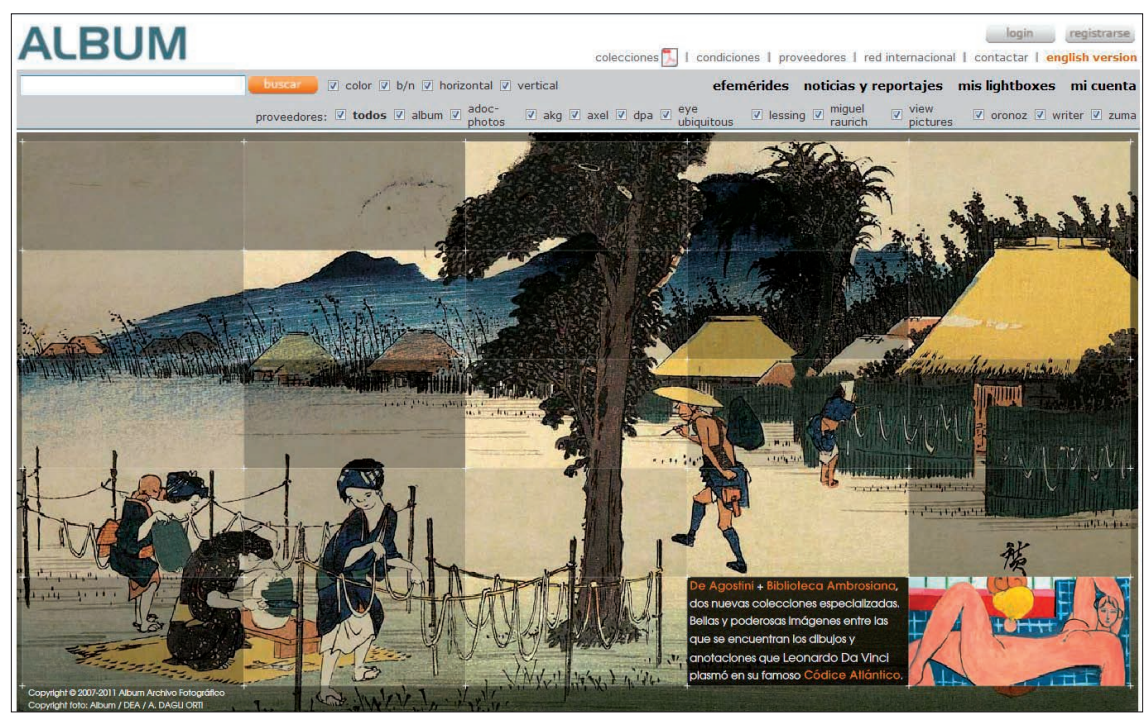

Figura 1. Web de Album, http://www.album-online.com soportes con varios anuncios implican un mayor uso de la imagen.

Se pretende con este estudio conocer el uso y comercio de la fotografía de los bancos de imágenes en publicidad a partir de la información facilitada por siete de las principales fototecas con negocio en España:

\begin{tabular}{|l|l|}
\hline Aisa & http://www.photoaisa.com \\
\hline Album & http://www.album-online.com \\
\hline Asa & http://www.asa-agency.com \\
\hline Latinstock & http://www.latinstock.es \\
\hline Quickimage & http://www.quick-image.com \\
\hline Prisma & http://www.prismaarchivo.com \\
\hline Oronoz & http://www.oronoz.com \\
\hline
\end{tabular}

\section{Antecedentes}

La fotografía forma parte del proceso comunicativo desde hace más de un siglo. La propuesta digital supuso un gran cambio hacia una imagen más participativa, más próxima al ciudadano y más fácil de realizar, pero no todos somos fotógrafos ni todas las fotos son publicables. En un contexto general, su estudio y análisis ha tenido importantes aportaciones. Sobre memoria colectiva citaremos los trabajos de Huguet-Chanza (2005), GómezDíaz; Gómez-Isla; Cordón-García; Astigarraga (2009), Torregrosa-Carmona (2010) y Cuenca-Jaramillo (2010). En cuanto a documentación y análisis son significativos Riego et al. (1997), Boadas; Casellas; Suquet (2001), MuñozCastaño (2001), Del-Valle-Gastaminza (2001), Robledano $(2000,2002)$ y Sánchez-Vigil (2007). De la recuperación y conservación en la Red han escrito Codina; Del-Valle-Palma (2001) y Doucet (2008). 


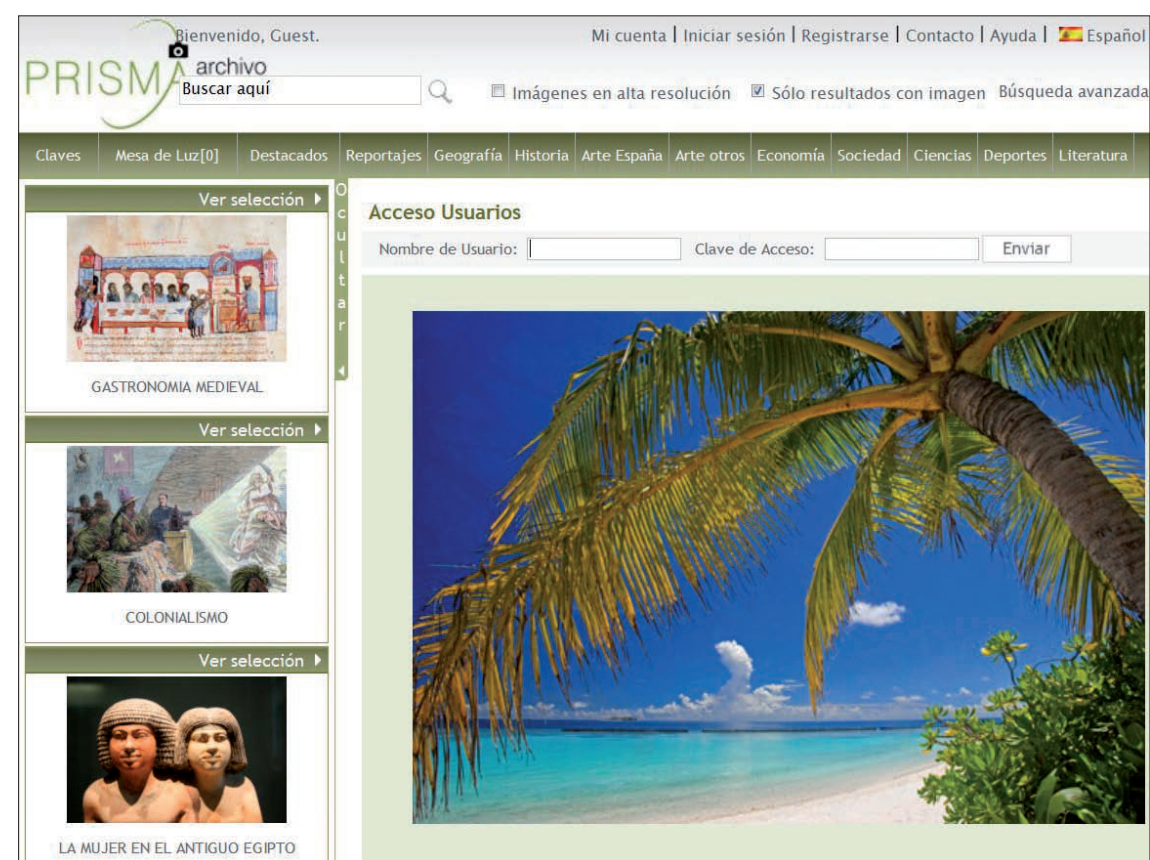

Figura 2. Web de Prisma, http://www.prismaarchivo.com

El uso y aplicación de la fotografía en prensa ha sido estudiado por Madrid-Díaz (1999), Mendizábal-Arzate (2008), López-Del-Ramo (2010) y Guallar; Rovira; Ruiz (2010), quienes han definido y estudiado aspectos informativos en los periódicos. Por lo que respecta a la industria editorial los trabajos son escasos, con un referente en Sánchez-Vigil, Marcos-Recio y Olivera-Zaldua (2010). Lo mismo sucede, como ya hemos comentado, con la publicidad, donde son pioneros los estudios de Eguizábal $(2001,2003)$ y MarcosRecio (2008) y en los últimos cuatro años la revista El publicista ha presentado tres reportajes (no 175, 2007; no 195, 2008, y no 235, 2010), más el artículo de Pérez-Montoro (2002) sobre nuevas tecnologías en los bancos de imágenes y su relación con la publicidad. La revista Yorokobu publicó un trabajo de Spottorno (2009) sobre la realidad de la fotografía en publicidad. Los antecedentes marcan por tanto pocos trabajos sobre el uso publicitario de la fotografía, que mueve cada año cifras millonarias, así como un escaso eco de la explotación comercial de las imágenes.

\section{Metodología}

Además de investigar los antecedentes y revisar la bibliografía sobre la materia, el método de trabajo ha sido la elaboración de un cuestionario (anexo) con 20 preguntas específicas en las que se ha incluido un campo final para los comentarios de los responsables de las fototecas. Como punto de partida se han establecido tres modelos de fototecas:

- productoras o con equipos de profesionales que generan material gráfico,

- distribuidoras si su función es la distribución de material de otras empresas, y/o

- mixtas si las funciones son ambas.

Han colaborado siete de las más importantes fototecas: dos grandes (Quickimage y Latinstock), tres medianas (Aisa, Album y Asa) y dos pequeñas (Prisma y Oronoz). No contestó a la petición la agencia Corbis, y declinaron la invitación a responder al cuestionario Daniel Gluckman de Getty y Al- fonso Gutiérrez de $A G E$, si bien éste nos remitió al blog de la agencia donde Gutiérrez (2011) valora la situación y actuación de las fototecas y agencias en el momento actual:

http://blog.agefotostock.com

Para este estudio se ha considerado suficiente el número de agencias, tanto por su tamaño como por su prestigio y función, ya que están representados los diferente modelos.

El cuestionario se distribuyó en enero de 2011 por correo electrónico, después de contactar con los responsables de cada una de las fototecas. Las respuestas se recibieron en el mes de marzo y todos los participantes lo consideraron interesante.

Los parámetros consultados fueron: fondos disponibles, su incremento anual, fotos digitalizadas, precios de las imágenes, fotos comercializadas en los últimos años, criterios de la demanda, garantías de derechos y exclusividad de uso, tratamiento documental, e importancia de internet en la difusión de contenidos.

\begin{tabular}{|l|l|}
\hline \multicolumn{1}{|c|}{ Fototeca } & \multicolumn{1}{c|}{ Especialidad } \\
\hline Aisa & Arte / Historia \\
\hline Album & Prensa / Edición \\
\hline Asa & Medio ambiente \\
\hline Latinstock & Gente / Estilos de vida / Negocios / Famosos \\
\hline Oronoz & Arte / Historia / Edición \\
\hline Prisma & Arte / Historia / Edición \\
\hline Quickimage & Estilo de vida / Viajes / Gastronomía \\
\hline
\end{tabular}

Tabla 1. Especialidad de las fototecas

\section{Fotógrafos y bancos de imágenes}

En una agencia de publicidad, antes de iniciar un proceso creativo se debe considerar si se encargará la imagen a un fotógrafo o si se utilizará la de un banco, ya que el procedimiento a seguir será diferente. En este sentido, Gutiérrez (2011) indica que las aportaciones de los fotógrafos (número de fotos) en Age han descendido un 6,2\% en el último año y sin embargo ha aumentado el número de autores en un $61 \%$.

Los publicitarios prefieren trabajar con un fotógrafo antes que acudir a un banco de imágenes porque se puede encargar exactamente lo que se quiere, ya que una fotografía de archivo no siempre se ajusta a las necesidades, como explica Moro en El publicista (2007): "En un mundo ideal preferiría fotógrafos, porque siempre te da más libertad creativa, que teniendo que partir de algo que ya estaba hecho. Sin embargo, en la práctica, teniendo en cuenta la premura de tiempo y que los presupuestos casi nunca permiten gran- 
des alegrías, trabajar con imágenes de archivo es una opción cada vez más interesante".

El uso de las imágenes publicitarias de las fototecas presenta como ventajas la rapidez, el ahorro en la inversión y la facilidad de uso. La respuesta de la fototeca es prácticamente inmediata, tanto si la búsqueda la realiza la empresa como si lo hace el interesado, y el precio supone un ahorro importante al evitar el proceso de producción. Hacer una buena foto requiere disponer de un excelente equipo humano y técnico, que interprete las ideas del creativo, conozca la industria publicitaria y que al final del proceso la foto ofrezca la deseada carga de información, pero la inversión es elevada y no todos los anunciantes disponen del presupuesto suficiente.

Por otra parte, además del uso inmediato la agencia permite la posibilidad de cambiar de imagen cuantas veces sea necesario hasta obtener el resultado deseado. La otra cara de la moneda está en el conformismo, con una imagen determinada que no se ajuste exactamente al objetivo del proyecto.

\section{Uso de la foto publicitaria: resultados}

Las siete fototecas seleccionadas para el estudio comercializan fotografías para publicidad directa o indirectamente (es decir, desde la propia empresa o a través de agencias intermediarias), bien de producción propia o bien sólo por distribución. Cinco de ellas son mixtas, es decir que producen imágenes y al mismo tiempo distribuyen material de otras empresas, mientras que Latinstock se considera sólo distribuidora y Oronoz productora. Todas las fototecas cuentan con material en depósito [propiedad de los fotógrafos] (tabla 2), los grandes grupos con un número elevado de autores (Latinstock y Quickimage), mientras que en las empresas medianas la representación varía entre los 50 y los 265 autores (Aisa, Album, Prisma, Asa). Oronoz, por su volumen de negocio, cuenta tan solo con fondo de 5 autores.

El uso publicitario de la fotografía se contempla en prensa, edición y campañas generales para empresas. Latinstock está especializada en campañas de todo tipo y la demanda es global en todos los campos, Quickimage cubre también

\begin{tabular}{|l|r|}
\hline \multicolumn{1}{|c|}{ Fototeca } & Autores \\
\hline Aisa & 65 \\
\hline Album & 50 \\
\hline Asa & 265 \\
\hline Latinstock & 1.000 \\
\hline Oronoz & 5 \\
\hline Prisma & 50 \\
\hline Quickimage & 250.000 \\
\hline
\end{tabular}

Tabla 2. Número de autores con fotografías en depósito
El uso de las imágenes de las fototecas presenta como ventajas la rapidez, el ahorro y la facilidad de uso

todos los sectores, con mayor demanda en campañas; Album y Prisma tienen mayor difusión en prensa y edición, mientras que Oronoz es productor de imágenes publicitarias y desarrolla su trabajo para editoriales. Las fotografías comercializadas varían considerablemente según el tamaño de la empresa y los sistemas de distribución: así en 2010 Quickimage facturó más de ocho millones de imágenes al precio medio de 2-3 euros, frente a las cerca de 6.000 de Latinkstock pero con un precio superior a los 200 euros. La facturación bruta anual de las dos grandes (Quickimage y Latinstock) ha descendido en más de un $30 \%$ en los dos últimos años. Las medianas y pequeñas han sufrido de igual forma el impacto de la crisis y todas la han soportado con la reducción de plantillas y el reajuste de precios.

La cantidad de imágenes en los bancos varía considerablemente, desde decenas de miles hasta millones. En el pasado año 2010 las 7 fototecas consideradas aumentaron su stock total en un $18 \%$ (el incremento medio fue del $10 \%$ ), pero ello no significa que la comercialización sea mayor, sino sólo que aumentó la oferta (tabla 3).

\begin{tabular}{|l|r|c|r|}
\hline \multicolumn{1}{|c|}{ Fototeca } & Total fotos & $\begin{array}{c}\text { Incremento } \\
\text { anual (\%) }\end{array}$ & Digitales \\
\hline Aisa & 1.250 .000 & 6 & 375.000 \\
\hline Album & 2.200 .000 & 20 & 1.200 .000 \\
\hline Asa & 500.000 & 15 & 500.000 \\
\hline Latinstock & 100.000 .000 & 20 & 20.000 .000 \\
\hline Oronoz & 250.000 & 2 & 62.500 \\
\hline Prisma & 500.000 & 5 & 250.000 \\
\hline Quickimage & 9.000 .000 & 2 & 9.000 .000 \\
\hline Total & 113.700 .000 & 18 & 31.387 .500 \\
\hline
\end{tabular}

Tabla 3. Fondos totales, incremento anual y digitales 


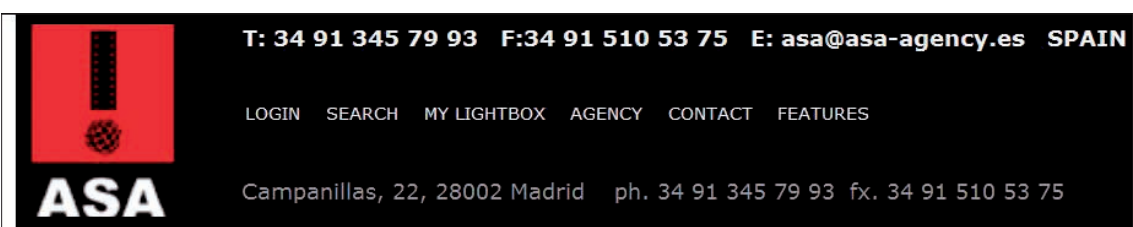

FEATURED STORY: Caral The Oldest City by George Steinmetz

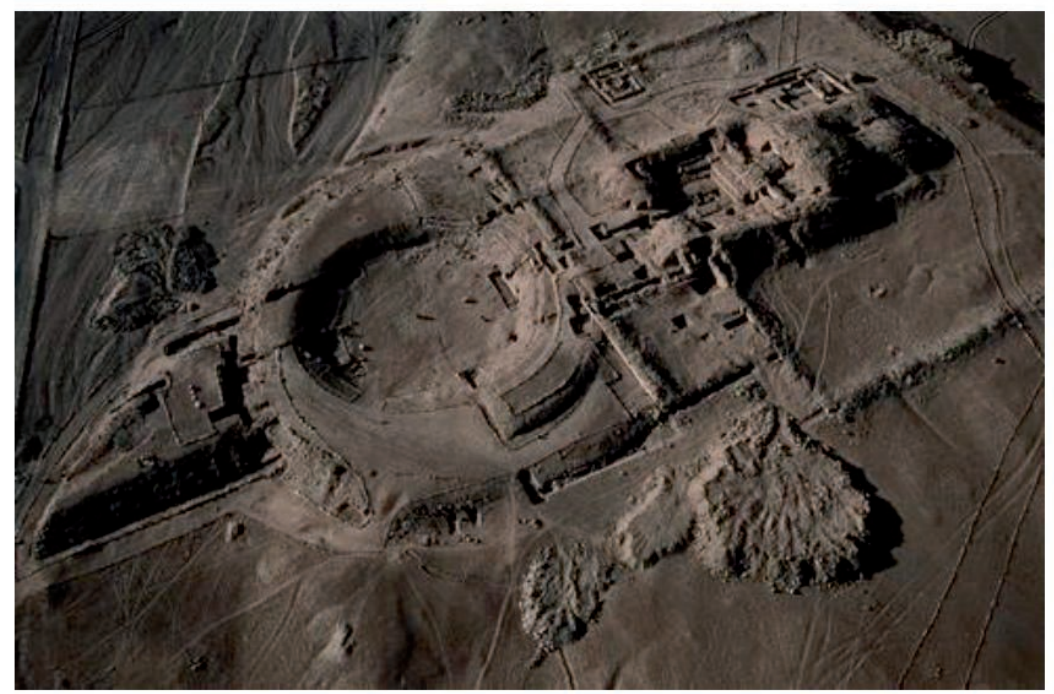

View slideshow I View Images

Caral se encuentra en el Valle de Supe, en Perú. La llamada civilización de Caral, propuesta por sus descubridores como la más antigua del continente americano fue coetánea de otras pueden considerarse como cuna de la civilización del mundo por su antigüedad.

Figura 4. Web de Asa, http://www.asa-agency.com

La digitalización es la asignatura pendiente. De las siete fototecas consultadas, sólo Quickimage y Asa tienen el $100 \%$ de las fotos digitalizadas, y todo su fondo puede ser consultado en la Red. El resto de empresas continúa digitalizando progresivamente, lo que ha supuesto y supone una fuerte inversión que debe ser amortizada (gráfico 1).

Por cuanto respecta a los criterios de demanda de las imágenes, en la mayoría de casos prima la relación contenidoprecio ya que la calidad en las fototecas estudiadas no sólo se presupone sino que se garantiza. Quickimage y Prisma señalan que el precio es factor determinante con respecto al contenido, por lo que en ocasiones se sacrifica la "fotografía ideal" por su alto coste, perdiendo así los máximos valores comunicativos por falta de presupuesto. generan una pequeña parte de su volumen de negocio, permiten dar salida a los fondos en stock (tabla 4).

Internet es fundamental para todas las agencias en la difusión y comercialización.

Para Quickimage la distribución por internet es más sencilla, rápida y con menor coste, pero la masificación y la gran oferta ha provocado la caída de los precios. Prisma señala que la Red beneficia por la posibilidad de llegar mejor y más rápido a todas partes, y perjudica porque en general se ofrece el mensaje "todo vale" y en consecuencia las imágenes pierden valor profesional y cala la idea de que cualquiera puede hacer una foto válida para su uso. Una de las cuestiones sobre el aumento de las fotos es la repercusión en su calidad. Latinstock entiende que la tecnología no es ni beneficiosa ni perjudicial, por lo que afronta el tema tratando de aprovechar la rapidez en la búsqueda y la mejor distribución del contenido.

Asa entiende que internet beneficia a los grandes grupos ya que pueden distribuir sus fondos ma-

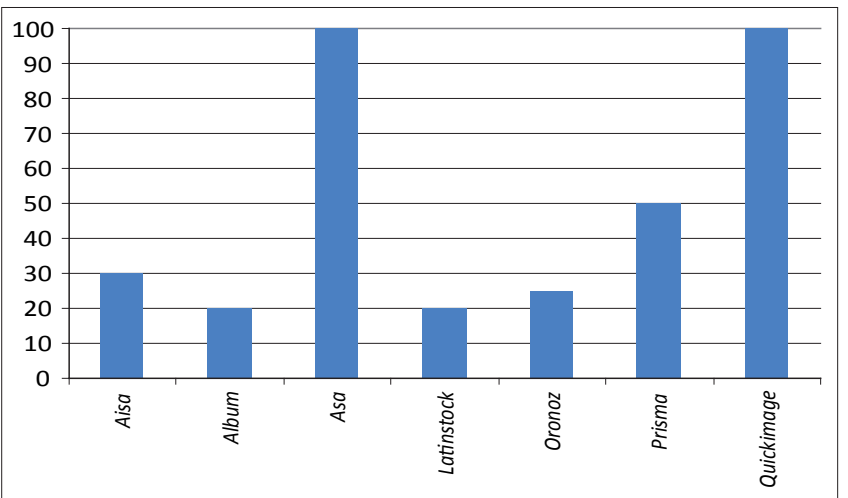

Gráfico 1. Porcentaje de fotografías digitalizadas
El precio medio es de 80 euros por foto, desde los 2-3 euros de Quickimage a los 228 de Latinstock, en una amplia oferta que depende del uso y aplicación, y por supuesto del sistema elegido para el alquiler (exclusiva, suscripción, foto única, grupo de imágenes, etc.). La oferta a bajo precio por suscripción y paquetes royalty free (conjunto de fotos libres de derechos para todo tipo de uso) de los grandes grupos es una de las cuestiones más debatidas, tanto por su efecto como por los resultados. Estos dos sistemas de venta (suscripción y paquetes libres de derechos) son rentables para las grandes agencias, ya que aunque sólo

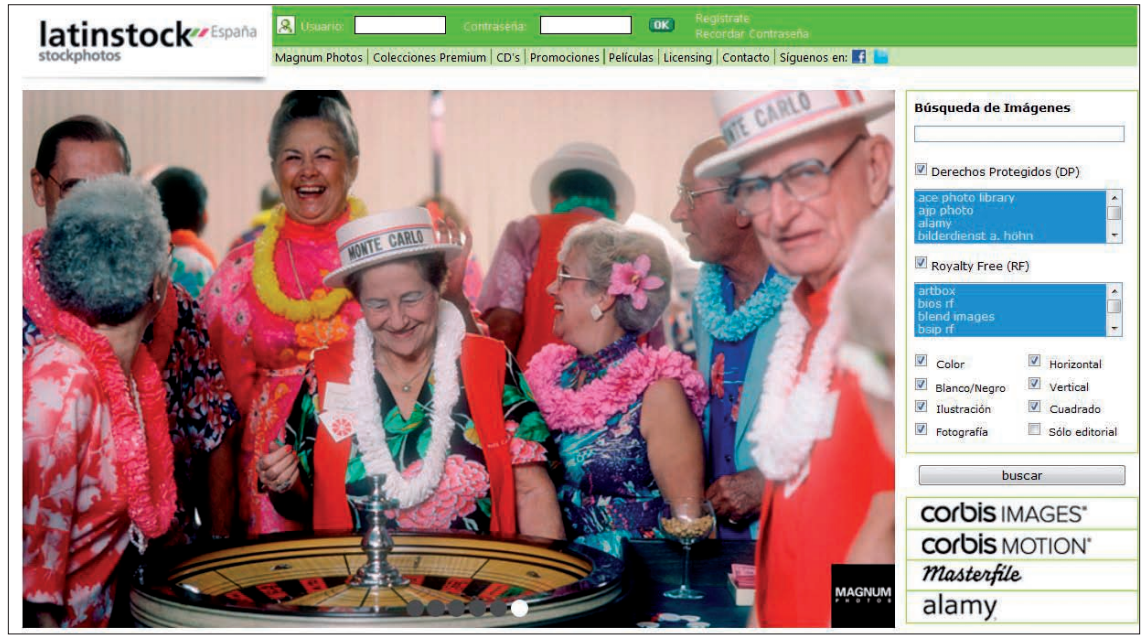

Figura 5. Web de Latinstock, http://www.latinstock.es 


\begin{tabular}{|l|c|c|c|}
\hline \multicolumn{1}{|c|}{ Fototeca } & $\begin{array}{c}\text { Demanda } \\
\text { por contenido }\end{array}$ & $\begin{array}{c}\text { Demanda } \\
\text { por precio }\end{array}$ & $\begin{array}{c}\text { Precio medio } \\
(€)\end{array}$ \\
\hline Aisa & $\mathrm{x}$ & $\mathrm{x}$ & 60 \\
\hline Album & $\mathrm{x}$ & $\mathrm{x}$ & 70 \\
\hline Asa & $\mathrm{x}$ & $\mathrm{x}$ & 110 \\
\hline Latinstock & $\mathrm{x}$ & $\mathrm{x}$ & 228 \\
\hline Oronoz & $\mathrm{x}$ & & 70 \\
\hline Prisma & $\mathrm{x}$ & $\mathrm{x}$ & 40 \\
\hline Quickimage & & $\mathrm{x}$ & 3 \\
\hline
\end{tabular}

Tabla 4. Criterios de demanda de los fondos y precio medio de las fotografías que el precio de las fotografías es un factor determinante y en publicidad cuando no se dispone de tiempo suficiente ni de presupuesto para acudir a un fotógrafo, la solución es acudir a un banco de imágenes.

Los planteamientos de las fototecas analizadas para aumentar y mejorar la comercialización de imágenes en publicidad se resumen en las acciones que se exponen a continuación a modo de conclusiones:

1. Mejora en la comercialización mediante contenidos especializados de alta calidad en la web, cuidada documentación y asignación de palabras clave, así como la clasi- sivamente, con ofertas por suscripción en las que mezclan cantidad y calidad. Considera entre los aspectos positivos la operatividad y rapidez en el trabajo, y como negativos la impaciencia del usuario, porque la inmediatez se asocia a la falta de criterios para el análisis y la búsqueda. La conclusión definitiva de Asa es que la distribución masiva perjudica al usuario y se produce un empobrecimiento visual (comprar en los mismos supermercados significa comprar imágenes semejantes), y por otra parte aboga por la recuperación de una figura profesional relegada o desaparecida, el picture editor o editor gráfico, cuya responsabilidad era la selección de imágenes.

Aunque se trate de temas tangentes a los objetivos de este artículo la encuesta indica que la mayoría de las fototecas garantizan la propiedad intelectual de sus imágenes, si bien Album matiza que hay casos en que puede haber derechos de terceros no gestionados por las agencias. Todas las fototecas estudiadas garantizan también la exclusividad de uso de la imagen en publicidad para evitar la duplicidad en la promoción de un mismo producto, aunque Prisma advierte del peligro que el autor deposite sus imágenes en más de una empresa.

\section{Conclusiones}

Los tiempos de la web 2.0 requieren de una actividad dinámica también en el uso de la fotografía en los medios de comunicación, especialmente en la publicidad, donde las campañas a veces se preparan en apenas dos semanas. Disponer de un banco de imágenes con fondos digitalizados ayuda de manera notable. Como se refleja en el estudio, las siete fototecas seleccionadas, en mayor o menor medida, trabajan con fotografía publicitaria. Se ha detectado

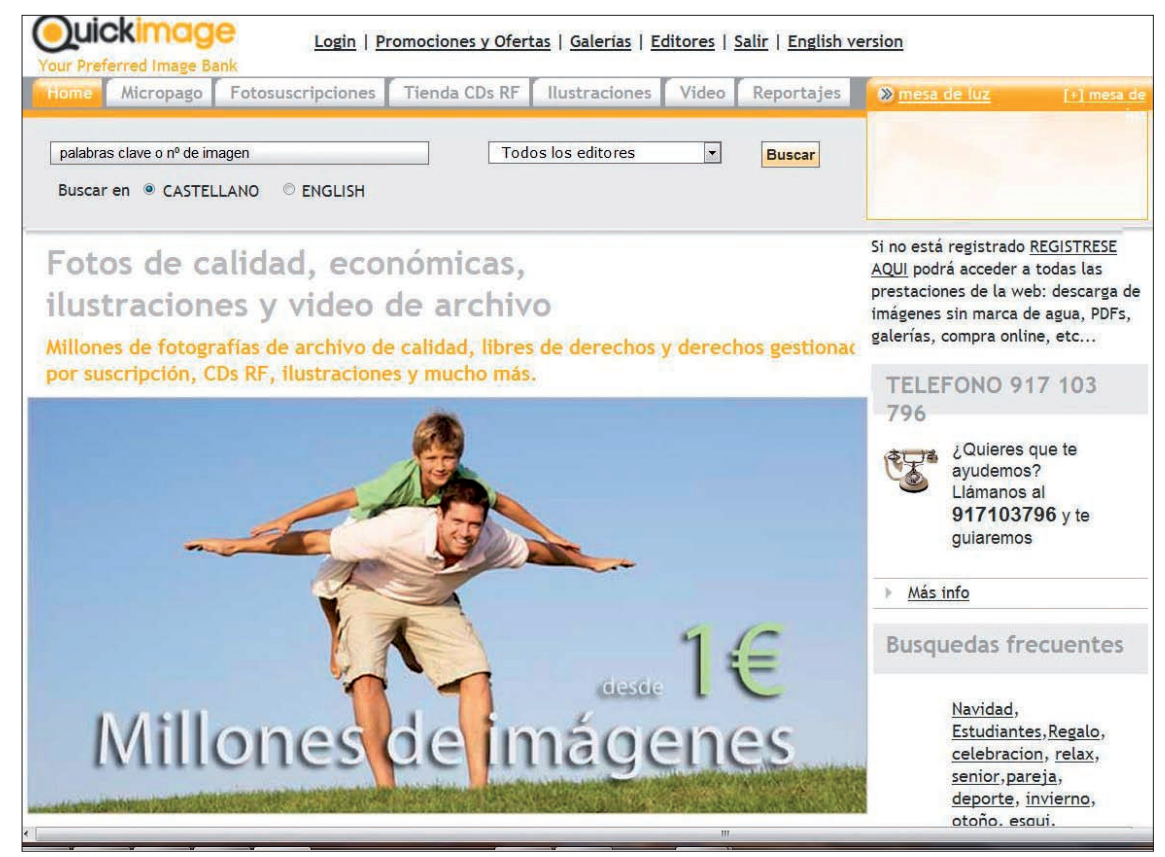

Figura 6. Web de Quickimage, http://www.quick-image.com

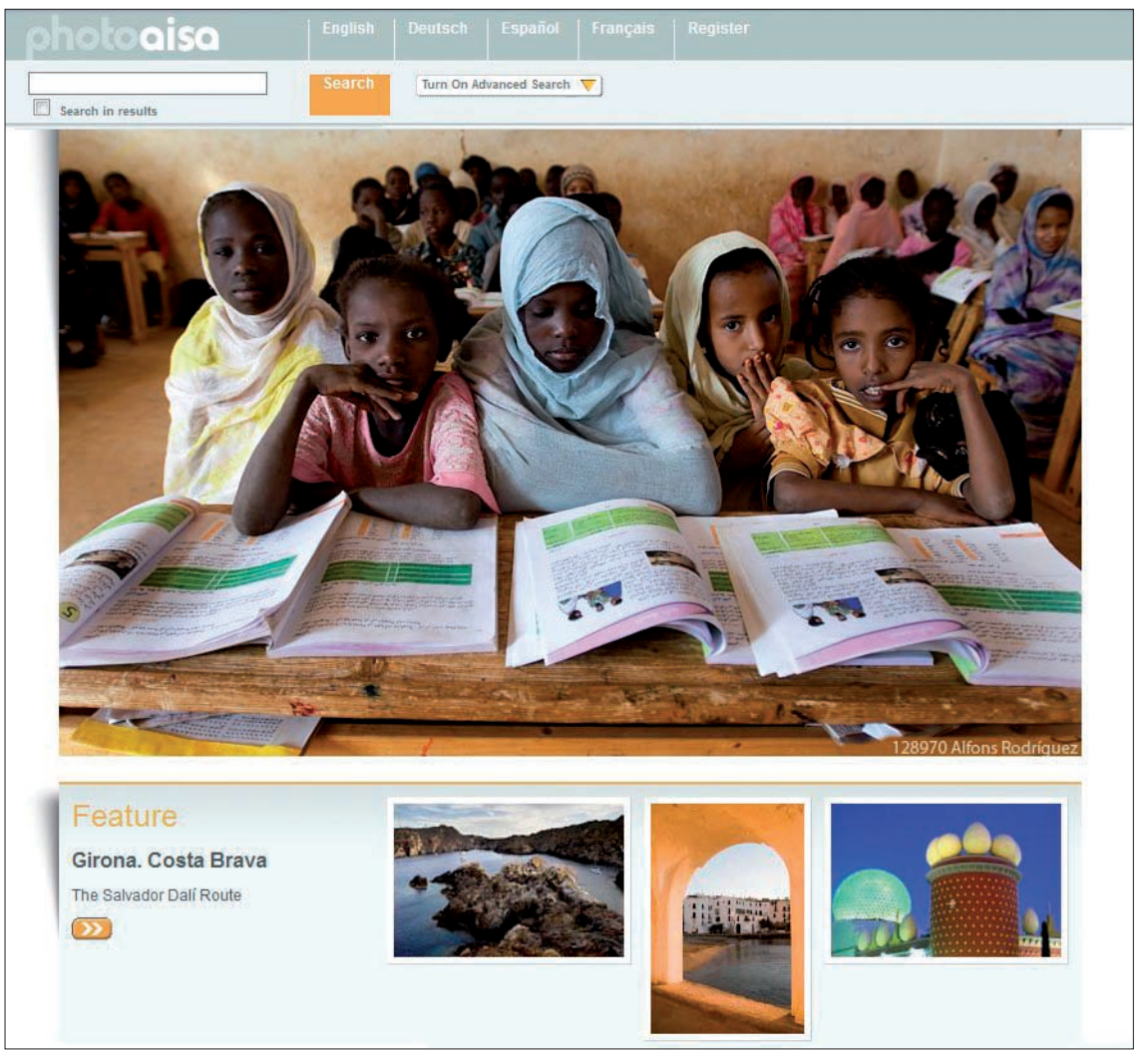

Figura 7. Web de Aisa, http://www.photoaisa.com 
ficación temática para ahorrar tiempo en las búsquedas (Album).

2. Conseguir el mejor contenido gráfico en exclusiva, entender y atender las necesidades del cliente para diseñar un proyecto a la carta (Latinstock).

3. Poner el máximo cuidado en la documentación de las imágenes (Oronoz).

4. Mantener la filosofía de la empresa adaptando las tecnologías a la demanda, dando entrada a nuevos formatos y estableciendo una política acorde al servicio prestado (Prisma).

5. Ofrecer más contenidos especializados y documentar mejor las imágenes (Quickimage).

6 . Buscar nuevos mercados en el ámbito cultural y de productos web (Asa).

\section{Bibliografía}

Boadas, Joan; Casellas, Lluís-Esteve; Suquet, Maria-Àngels. Manual para la gestión de fondos y colecciones fotográficas. Barcelona: CCG Ediciones, 2001. ISBN: 85-95483-11-4.

Codina, Lluís; Del-Valle-Palma, María. "Bancos de imágenes y sonido y motores de indización en la WWW". Revista española de documentación científica, 2001, v. 24, n. 3, pp. 251-274.

Cuenca-Jaramillo, María-Dolores. Bancos de imágenes (investigación, conservación y difusión del patrimonio cultural). Tesis doctoral defendida en la Facultad de Ciencias de la Información de la UCM, Madrid, 2010.

Del-Valle-Gastaminza, Félix. El análisis documental de la fotografía, 2001.

http://www.ucm.es/info/multidoc/prof/valle/artfot.htm

Doucet, Anne-Vinciane. "La descripción de imágenes en internet a través del análisis de 30 bancos de imágenes". Revista general de información y documentación, 2008, v. 18, pp. 81-105.

Eguizábal-Maza, Raúl. Fotografía publicitaria. Madrid: Cátedra, 2001, ISBN 978-84-376-1919-4.

Eguizábal-Maza, Raúl. "La fotografía moderna, de la publicidad a la propaganda". A distancia, 2003, n. 1, pp. 161-171.

Gómez-Díaz, Raquel; Gómez-Isla, José; Cordón-García, José-Antonio; Domínguez-López, Juan-José. “El patrimonio fotográfico de la Universidad de Salamanca: la creación de una fototeca digital". Ibersid, 2007, pp. 177-194.

Guallar, Javier; Rovira, Cristófol; Ruiz, Sara. "Multimedialidad en la prensa digital. Elementos multimedia y sistemas de recuperación en los principales diarios españoles". El profesional de la información, 2010, noviembre-diciembre, v. 19, n. 6 , pp. 620-629.

Gutiérrez, Alfonso. "AGE Fotostock: de cara a 2011 y más allá".

http://blog.agefotostock.com/post/2011/01/25

Huguet-Chanzá, José. "Fotografía, memoria colectiva y archivos". Archivo de arte valenciano, 2005, n. 86, pp. 269279.

López-Del-Ramo, Joaquín. “Configuración y contextualiza- ción de las galerías fotográficas en los diarios on-line. Propuesta de analítica aplicada. El profesional de la información, 2010, septiembre-octubre, v. 19, n. 5, pp. 469-475.

López-Del-Ramo, Joaquín. "El tratamiento fotoperiodístico en las portadas de los diarios digitales. Propuesta y aplicación de un modelo de análisis". Doxa comunicación, 2010, n. 11, pp. 77-99.

Madrid-Díaz, María V. Análisis documental: fotografía de prensa. En: Antonio García-Gutiérrez (ed.). Introducción a la documentación informativa y periodística. Alcalá de Guadaira: Mad, 1999, pp. 305-331.

Marcos-Recio, Juan C. "La fotografía en la publicidad: archivos, bancos de imágenes y centros de documentación en el siglo XXI". En: Pacheco-Rueda, Marta (coord.). La publicidad en el contexto digital. Viejos retos y nuevas oportunidades. Sevilla: Comunicación Social. Ediciones y publicaciones, 2008, pp. 87-112. ISBN 978-84-96082-71-7.

Mendizábal-Arzate, María-Elizabeth. Análisis documental, recuperación y medidas de preservación de la fotografía de prensa. México: Facultad de Filosofía y Letras. Colegio de Bibliotecología. Universidad Nacional Autónoma de México, 2008.

http://www.filos.unam.mx/LICENCIATURA/bibliotecologia/ textos-apoyo-docencia/mendizabal-arzate-maria-elizabeth. pdf

Muñoz-Castaño, Jesús E. "Bancos de imágenes: evaluación y análisis de los mecanismos de recuperación de imágenes". El profesional de la información, 2001, marzo, v. 10, n. 3, pp. 4-18.

Pérez-Montoro, Mario. "Banco de imágenes. Más que mil palabras". El publicista, 2002, 16 oct., pp. 12-15.

El publicista. "Bancos de imagen: no sólo fotos. El mundo de los archivos de imágenes evoluciona". El publicista, 2007, n. 175, enero, pp. 16-27.

El publicista. "Bancos de imagen: creatividad y racionalidad en los costes". El publicista, 2008, 1-15 diciembre, n. 235, pp. 40-45.

El publicista. "Los bancos de imágenes opinan". El publicista, 2010, 1-15 diciembre, pp. 24-28.

Riego, Bernardo; Alonso-Laza, Manuela; Muñoz-Benavente, Teresa; Argerich, Isabel; Fuentes-De-Cêa, Àngel. Manual para el uso de archivos fotográficos. Madrid: Ministerio de Cultura, 1997. ISBN: 84-923240-0-7.

Robledano-Arillo, Jesús. El tratamiento documental de la fotografía en prensa: sistemas de análisis y recuperación. Madrid: Archiviana, 2002.

Robledano-Arillo, Jesús. Documentación fotográfica en medios de comunicación social. En: Moreiro-González, JoséAntonio. Manual de documentación informativa. Madrid: Cátedra, 200, pp. 183-290.

Sánchez-Vigil, Juan-Miguel. El documento fotográfico: historia, usos, aplicaciones. Gijón: Trea, 2007, ISBN 978-849704-223-9.

Sánchez-Vigil, Juan-Miguel; Marcos-Recio, Juan-Carlos; 
Olivera-Zaldua, María. "Evolución de los departamentos de comunicación en las editoriales". El profesional de la información, 2010, enero-febrero, n. 19, v. 1, pp. 52-56.

Spottorno, Carlos. "El prodigioso renacimiento de la fotografía". Yorokobu, 2009, diciembre, n. 2, pp. 56-61.
Torregrosa-Carmona, Juan-Francisco. "Modelos para el análisis documental de la fotografía". Documentación de las ciencias de la información, 2010, v. 33, pp. 329-342.

\section{Anexo. Cuestionario}

1. Su fototeca es

Productora

Distribuidora

Mixta

2. ¿Trabajan en régimen de depósito con los autores?

Sí $\square$ No $\square$

3. Número de autores con fotografías depositadas en la fototeca/agencia

Cantidad totalde fotogafiasque tieneen

4. Cantidad total de fotografías que tienen en su fondo

5. ¿En qué número se incrementa anualmente el fondo?

6. Porcentaje de fotografías digitales o digitalizadas

¿Es consultable todo el fondo en red?

Sí $\square$ No

En caso negativo porcentaje consultable

Precio medio de cada fotografia

8. Precio medio de cada fotografía

9. Número de fotografías comercializadas en los últimos cinco años

$2005 \square 2006 \square 2007 \square 2009 \square$

10. Indique los criterios de demanda de las fotografías por las empresas/agencias Contenido $\square$ Precio $\square$ Relación contenido/precio

11. Indique la principal aplicación de la fotografía de su fondo

Campañas generales Campañas específicas (indique)

12. Indique la materia más rentable para su fototeca (por ejemplo viaje, motor, sociedad, alimentación, etc.)



13. ¿Ofertan paquetes royalty free?

Sí

Precio medio del número de fotografías por paquete

14. ¿Garantizan la propiedad intelectual de la fotografía?

Sí

En caso negativo ¿de quién depende la garantía?

15. ¿Garantizan la exclusividad de la fotografía para evitar doble o más usos por la competencia?

Sí $\square$ No

16. ¿Se documentan las fotografías?

Sí $\square$ No

En caso negativo ¿quién realiza la tarea?

En caso positivo ¿realizan el análisis documental completo?

Contenido Continente

17. Considera que el software y motor de búsqueda dan la respuesta adecuada

Sí

En caso positivo tiempo medio de respuesta

En caso negativo ¿qué mejoraría?

Motor de búsqueda $\square$ Base de datos $\square$ Otro (indique)

18. Influencia de internet en el negocio (Comentar)

19. Planteamientos de futuro para la mejora de la comercialización del fondo

20. Facturación bruta anual de los cinco últimos años 2005 2006 2007 2008 2009 2010 